\title{
The Biosynthesis of Gangliosides
}

\author{
LABELLING OF RAT BRAIN GANGLIOSIDES IN VIVO
}

\author{
By H. J. MACCIONI, A. ARCE* and R. CAPUTTO \\ Departamento de Química Biológica, Facultad de Ciencias Químicas, Universidad Nacional de \\ Córdoba, Ciudad Universitaria, Córdoba, Argentina
}

(Received 29 July 1971)

\begin{abstract}
1. After injection of $\left[6-{ }^{3} \mathrm{H}\right]$ glucosamine into 8-day-old rats it was found that all the major brain gangliosides and their sialyl groups were labelled at essentially the same rate, except the hematoside, which was the least labelled. In 18-day-old rats it was found that the two major gangliosides with the sialyl $(2 \rightarrow 8)$-sialyl linkage, and their sialyl groups were more labelled than the hematoside, the Tay-Sachs ganglioside, the other two major gangliosides and their respective sialyl groups. 2. No difference was found in any of the cases studied between the specific radioactivities of the neuraminidase-resistant and -labile sialyl groups belonging to the same ganglioside. The same was found for the specific radioactivities of the galactosyl groups proximal and distal to the ceramide moiety of total brain gangliosides from rats injected with $\left[\mathrm{U}-{ }^{14} \mathrm{C}\right]$ glucose. From this it was concluded that partial turnover of the ganglioside molecule does not occur. 3. A model for the synthesis of gangliosides is presented that accounts for results from previous experiments in vitro and the lack of precursor-product relationships observed in experiments in vivo.
\end{abstract}

Pathways for the synthesis of the carbohydrate chain of gangliosides have been worked out from experiments in vitro by using either exogenous or endogenous acceptors of glycosidic groups (Kaufman, Basu \& Roseman, 1966, 1968; Arce, Maccioni \& Caputto, 1966, 1971; Cumar, Fishman \& Brady, 1971). Whereas there is general agreement among the investigators about the sugar nucleotide donors of those groups some minor discrepancies on the sequence of addition at the branching point still persist (for a review of the current situation see Arce et al. 1971). It should be pointed out, however, that another difficulty has not yet been solved, the results of labelling in vivo can not be readily correlated with those expected from the pathways worked out in vitro. It has been reported, for instance, that after giving $\left[{ }^{14} \mathrm{C}\right]$ glucose (Suzuki \& Korey, 1964) or $\left[{ }^{3} \mathrm{H}\right]$ glucosamine (Arce, Maccioni \& Caputto, 1970) to rats no precursor-product relationships were found between G GNT $1 \dagger$ and

* Present address: Facultad de Ciencias Exactas, Físicas y Naturales, and Instituto de Ciencias Agronómicas, Universidad Nacional de Córdoba, Córdoba, Argentina.

$\dagger$ Abbreviations: NeuNAc, $N$-acetylneuraminic acid. For gangliosides, the abbreviation system based on structural considerations (Wiegandt, 1968) has been used. Hematoside $G$ Lac $1, N$-acetylneuraminyl- $(2 \rightarrow 3)$. galactosyl-(1 $\rightarrow$ 4)-glucosylceramide; G Lac 2, $N$-acetyl-
G GNT 2a and G GNT 3. Also, the finding that the neuraminidase-resistant NeuNAc was more highly labelled than the neuraminidase-labile NeuNAc of the same molecule (Suzuki \& Korey, 1964) in rats that had received $\left[{ }^{14} \mathrm{C}\right]$ glucose, if correct, is difficult to reconcile with those pathways unless other specifications are added to them.

In the present work an effort was made to measure the labelling in vivo of G Lac 1. This ganglioside is assumed to be a common precursor to all the major

neuraminyl - $(2 \rightarrow 8)$ - $N$ - acetyl - neuraminyl - $(2 \rightarrow 3)$ galactosyl-( $1 \rightarrow 4)$-glucosylceramide; Tay-Sachs ganglioside G GNTr $1, N$-acetylgalactosaminyl- $(1 \rightarrow 4)-[N$ acetylneuraminyl - $(2 \rightarrow 3)]$ - galactosyl - $(1 \rightarrow 4)$ - glucosyl ceramide; monosialoganglioside G GNT 1, galactosyl$(1 \rightarrow 3)$ - $N$ - acetylgalactosaminyl - $(1 \rightarrow 4)-[N$ - acetyl neuraminyl - $(2 \rightarrow 3)]$ - galactosyl- $(1 \rightarrow 4)$-glucosylceramide; disialoganglioside G GNT 2a, $N$-acetylneuraminyl$(2 \rightarrow 3)$ - galactosyl - $(1 \rightarrow 3)$ - $N$-acetylgalactosaminyl $(1 \rightarrow 4)$ - $[N$ - acetylneuraminyl - $(2 \rightarrow 3)]$ - galactosyl - $(1 \rightarrow 4)$ glucosylceramide; disialoganglioside G GNT $2 \mathrm{~b}$, galactosyl - $(1 \rightarrow 3)$ - $N$ - acetylgalactosaminyl - $(1 \rightarrow 4)$ - $[N$ - acetyl neuraminyl - $(2 \rightarrow 8)-N$ - acetylneuraminyl - $(2 \rightarrow 3)]$ galactosyl-(1 $\rightarrow 4)$-glucosylceramide; trisialoganglioside $\mathbf{G}$ GNT $3, \quad N$-acetylneuraminyl-(2 $\rightarrow 3)$-galactosyl-(1 $\rightarrow 3)$ $\mathrm{N}$ - acetylgalactosaminyl - $(1 \rightarrow 4)-[N$ - acetylneuraminyl $(2 \rightarrow 8)$ - $N$ - acetylneuraminyl - $(2 \rightarrow 3)]$-galactosyl - $(1 \rightarrow 4)$ glucosylceramide; G Lac, galactosyl-(l $\rightarrow 4)$-glucosylceramide. 
gangliosides and the size of its pool is relatively small. It was therefore expected that during early periods after giving the labelled precursor the differences between the specific radioactivities of G Lac 1 and the major gangliosides would be large if a precursor-product relationship really exists. In addition, the labelling of the two galactosyl and two of the sialyl groups of the same ganglioside was compared. Although the results did not completely confirm those of Suzuki \& Korey (1964) they were not in agreement with those expected from a system of substrates free in solution. However, when the results in vivo were considered in relation to our previous studies on the kinetics of incorporation of labelled glycosidic groups into endogenous acceptors (Arce et al. 1971) we were able to suggest a model of multienzyme-substrate units that may be useful as a general model for the synthesis of structural components of the cell.

\section{EXPERIMENTAL}

Animals. Albino rats either 8 or 18 days old were used. Labelled precursors were administered intracerebrally or intraperitoneally, as is stated in each case. After receiving the injection the rats were returned to their mother until they were decapitated. The brains were immediately removed and pooled in methanol at $-14^{\circ} \mathrm{C}$. To compensate for individual variations, at least ten brains were taken for each determination.

Gangliosides were extracted by the method of Folch, Lees \& Sloane-Stanley (1957); the extracts were partitioned with water. The gangliosides were isolated from the upper phase and purified as described by Arce et al. (1971). The specific radioactivity of each of the major gangliosides did not change after they were successively subjected to t.l.c. with propanol-water $(7: 2.3, v / v)$ as solvent and passed through a column of Sephadex G-25 (Wells \& Dittmer, 1963). The specific radioactivities of the neuraminidase-labile and -resistant NeuNAc from gangliosides were determined as previously described (Arce et al. 1971).

Radioactive compounds. These were obtained from New England Nuclear Corp., Boston, Mass., U.S.A., and had the following specific radioactivities: $\left[6-{ }^{3} \mathrm{H}\right]$ glucosamine, $1.5 \mathrm{Ci} / \mathrm{mmol}$; [U.-14 $\mathrm{C}$ ]glucose, $170 \mathrm{mCi} / \mathrm{mmol}$.

Isolation of the galactosyl groups proximal and distal with respect to the ceramide moiety. After isolation by dialysis of the neuraminidase-resistant NeuNAc (see Arce et al. 1971) the non-diffusible fractions from the major gangliosides obtained at different periods after injection of the labelled precursor (containing approx. $1-1.5 \mu \mathrm{mol}$ of ceramide) were pooled. This pool was hydrolysed for $1 \mathrm{~h}$ at $100^{\circ} \mathrm{C}$ in $0.5 \mathrm{ml}$ of $0.1 \mathrm{M}-\mathrm{HCl}$; the products of hydrolysis were run on t.l.c. on silica gel G (Merck A.-G., Darmstadt, Germany) with chloroform-methanol-conc. $\mathrm{NH}_{3}$ (sp.gr. 0.88) (66:30:5, by vol.) as solvent. Lactosylceramide and tetrahexosylceramide were isolated by using as reference authentic standards from bovine brain gangliosides obtained as described by Cumar, Barra, Maccioni \& Caputto (1968). The plate was exposed to iodine vapour to locate the glycolipids. When the excess of iodine had evaporated the zones corresponding to each hexosylceramide were scraped off and the lipid eluted with chloroform-methanol-water (10:10:3, by vol.) (Ledeen, Salsman \& Cabrera, 1968).

Samples of the eluates were checked by t.l.c. with chloroform-methanol-water (33:15:2, by vol.); after spraying with the anthrone reagent and heating they showed a single spot corresponding, respectively, to lactosylceramide and tetrahexosylceramide. Each of them was hydrolysed for $7 \mathrm{~h}$ at $100^{\circ} \mathrm{C}$ in $3 \mathrm{M}-\mathrm{HCl}$, partitioned with chloroform, and the upper phase evaporated. Traces of $\mathrm{HCl}$ were eliminated by evaporation after repeated additions of methanol, and the hexose mixture was passed successively through columns of Dowex $50\left(\mathrm{H}^{+}\right.$form $)$and Dowex 1 (formate form). The effluent containing the neutral hexoses was freeze-dried in test-tubes; to each tube, $1.5 \mu \mathrm{mol}$ of $\mathrm{MgCl}_{2}, 1.5 \mu \mathrm{mol}$ of ATP, 0.8 unit of hexokinase (yeast Type III; Sigma Chemical Co., St Louis, Mo., U.S.A.) and $20 \mu \mathrm{mol}$ of tris chloride buffer, pH8, were added in a final volume of $0.2 \mathrm{ml}$; after incubation for $3 \mathrm{~h}$ at $37^{\circ} \mathrm{C}$ the mixture was heated for $1.5 \mathrm{~min}$ at $100^{\circ} \mathrm{C}$, centrifuged and the supernatant was passed again through columns of Dowex $50\left(\mathrm{H}^{+}\right.$form) and Dowex 1 (formate form). Galactose was the only sugar detected by t.l.c. (Gal, 1968) in a sample of the effluent; it was determined and its specific radioactivity measured. Glucose 6phosphate was eluted from the Dowex 1 column with $0.5 \mathrm{M}-\mathrm{HCl}$ and its total radioactivity determined. Since in lactosylceramide the glucose/galactose molar ratio is 1 , the specific radioactivity of glucose was calculated from the total counts measured in the glucose 6-phosphate fraction and the amount of galactose determined for the same sample of lactosylceramide. The specific radioactivity of the galactose distal to the ceramide moiety from the tetrasaccharide chain was calculated from:

$\frac{\text { Sp. rad. proximal Gal }+ \text { Sp. rad. distal Gal }}{2}=$

Sp. rad. total Gal,

where Sp. rad. proximal Gal was the specific radioactivity of the galactose isolated from lactosylceramide and Sp. rad. total Gal was the specific radioactivity of the galactose isolated from tetrahexosylceramide.

Chemical determinations. For determinations of free NeuNAc either the method of Aminoff (1961) or that of Svennerholm modified by Miettinen \& Takki-Luukkainen (1959) were used; the last method was applied for bound NeuNAc. Hexoses were determined by the anthrone reaction (Trevelyan \& Harrison, 1952).

\section{RESULTS}

Labelling of the different gangliosides. Fig. 1(a) shows the total labelling of each ganglioside expressed as c.p.m./ $\mu \mathrm{mol}$ of NeuNAc after $\left[6{ }^{3} \mathrm{H}\right]-$ glucosamine was injected intracerebrally into 8-day-old rats. In these animals the labelling of the major gangliosides was, in decreasing order, $G$ GNT 1, G GNT 3, G GNT $2 b$ and G GNT 2a. However, with the exception of the lowest specific radioactivity of G Lac 1, a clear pattern of differences between the various gangliosides could not be 
established. All of the gangliosides reached maximum specific radioactivities at about $3 \mathrm{~h}$ after injection. This picture changed substantially in the 18-day-old rats (Fig. $1 b$ ); in these animals the major gangliosides could be divided into two groups: G GNT 2b and G GNT 3 had higher specific radioactivities than G GNT 1 and G GNT $2 \mathrm{a}$; this difference was maintained from $5 \mathrm{~h}$ to 12 days. In experiments not included in Fig. $1(b)$, this difference was observed also at 40,60 and $120 \mathrm{~min}$ after injection. Both at 8 and 18 days of age the total labelling of G Lac 1 was lower than that of the major gangliosides. This observation, however, does not preclude the possible role of G Lac 1 as precursor of the more complex gangliosides, because the difference could be due to the labelling of the galactosaminyl groups in the major gangliosides (in G GNT 1 from rats of 18 days of age, $24 \mathrm{~h}$ after injection, the specific radioactivities of the galactosaminyl and sialyl groups were respectively 19300 and 8709 c.p.m. $/ \mu \mathrm{mol})$.

Labelling of the sialyl groups. The presence on the t.l.c. plates was noted of a compound which ran with G GNT 1 and which contained a neuraminidase-labile sialic acid. From its chromatographic mobility this presumed ganglioside could be either a-hitherto undescribed monosialoganglioside or else G Lac 2 (Kuhn \& Wiegandt, 1964). Unfortunately, the amounts found were too small

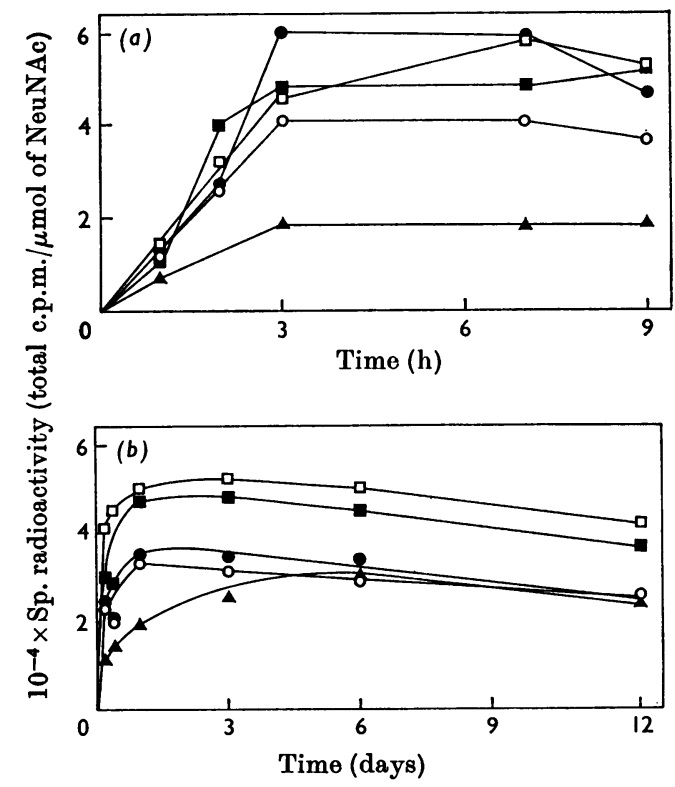

Fig. 1. Labelling of rat brain gangliosides as a function of time after intracisternal injection of $5 \mu$ l of $0.9 \% \mathrm{NaCl}$ containing $50 \mu \mathrm{Ci}$ of $\left[6^{-3} \mathrm{H}\right]$ glucosamine. (a) Rats 8 days old; (b) rats 18 days old. $\triangle$, G Lac 1;, , G GNT 1; O, G GNT 2a; $\square$, G GNT 2b;, , G GNT 3. to characterize it. No further consideration will be given to this compound in the present work, except to say that the labelling of its sialyl group was of the same order as those from G GNT $2 b$ and G GNT 3 in the 18-day-old rats and between those of G Lac 1 and G GNT $2 a$ in the 8-day-old rats.

In 8-day-old rats (Fig. 2) there were no clear differences among the specific radioactivities of the NeuNAc residues from different gangliosides, except the NeuNAc residue from G Lac 1, which was less labelled. No differences were found between the specific radioactivities of the neuraminidase-resistant and -labile NeuNAc groups from each multisialoganglioside; this is not in agreement with the results reported by Suzuki \& Korey (1964), according to which in 8-day-old rats injected with $\left[\mathrm{U}-{ }^{14} \mathrm{C}\right]$ glucose the specific radioactivity of the neuraminidase-resistant NeuNAc groups from multisialogangliosides was 2 to 3 times that of the neuraminidase-labile NeuNAc groups. We considered at first that differences found in our earliest experiments in vivo were significant (see Arce et al. 1971, p. 484) but after completing four series of experiments we concluded that after injection of either [U-14C]glucose or $\left[6{ }^{3} \mathrm{H}\right]$ glucosamine there were no definite differences between the labelling of each NeuNAc moiety in a given multisialoganglioside (Table 1 , Fig. 2).

In 18-day-old rats (Fig. 3) the specific radioactivities of the sialyl groups from G GNT $2 \mathrm{~b}$ and G GNT 3 were approximately twice as high as those obtained from G GNT 1 and G GNT 2a. The values for the NeuNAc groups from G Lac 1 were initially between the values for G GNT 1 and $G$ GNT $2 b$ and at the sixth day after injection similar to those of G GNT $2 \mathrm{~b}$ and G GNT 3. Here again, comparison of the specific radioactivities of the neuraminidaseresistant and -labile NeuNAc groups from a given multisialoganglioside shows that they were labelled at essentially the same rate; this was so also for the two labile NeuNAc groups from G GNT 3. In different experiments, the ratio between the specific radioactivities of the neuraminidaseresistant and -labile sialyl groups varied between 0.8 and 1.2 .

Labelling of the hexose moieties. There was practically no labelling of the galactosyl and glucosyl residues of gangliosides after 18-day-old rats were injected with $\left[6{ }^{3} \mathrm{H}\right]$ glucosamine; the specific radioactivity of the neutral hexose mixture in the period 24-72h was in most cases 250c.p.m./ $\mu \mathrm{mol}$ or less, this value being approx. 50-100-fold lower than that of the sialyl groups in the different gangliosides. On the other hand, when [U- ${ }^{14} \mathrm{C}$ ]glucose was the precursor, the hexoses accounted for about $80 \%$ of the total radioactivity of the ganglioside molecule. The specific radioactivities of 


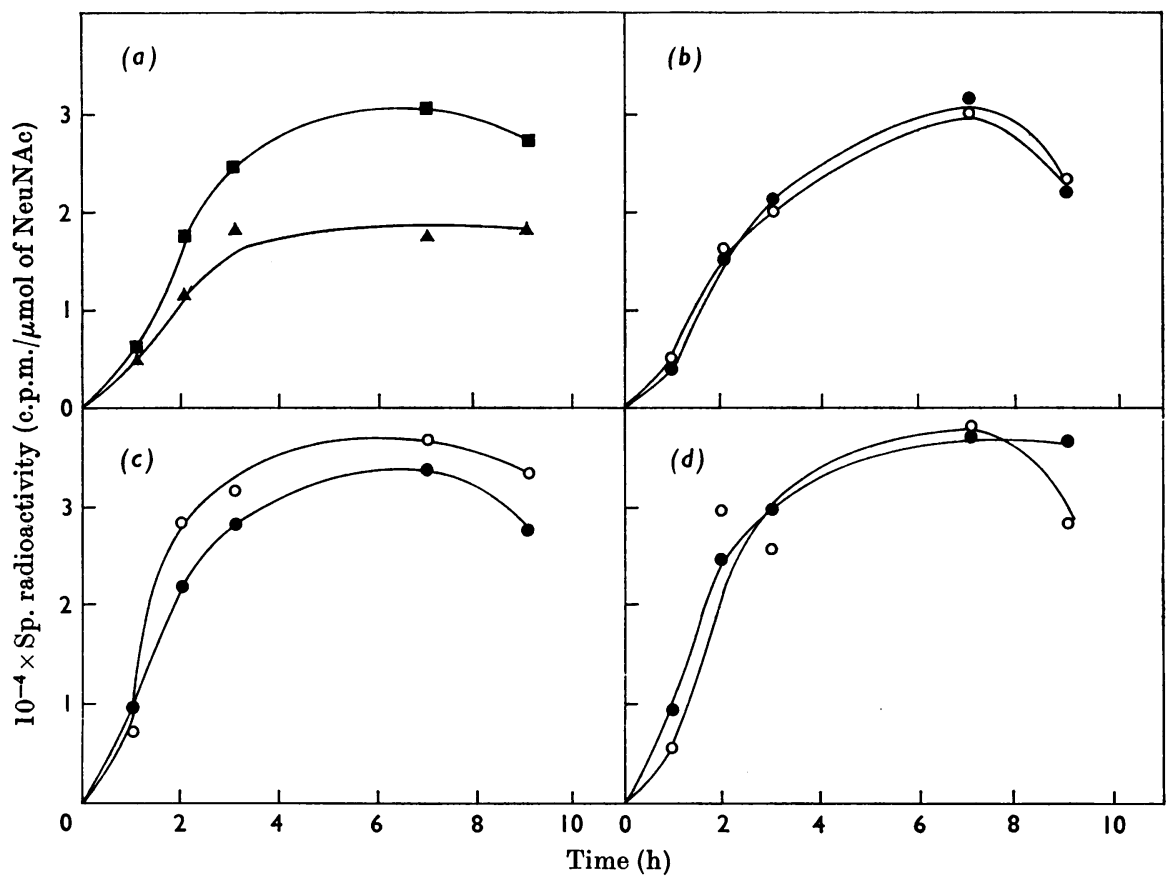

Fig. 2. Labelling of NeuNAc groups from brain gangliosides as a function of time after intracisternal injection of $5 \mu \mathrm{l}$ of $0.9 \% \mathrm{NaCl}$ containing $50 \mu \mathrm{Ci}$ of $\left[6^{-3} \mathrm{H}\right]$ glucosamine in 8-day-old rats. The following symbols are used in the cases of G GNT $2 a(b)$, G GNT $2 b(c)$ and G GNT $3(d): \bullet$, neuraminidase-resistant NeuNAc; $O$, neuraminidase-labile NeuNAc; for G GNT 3 the values for the labile fraction represent the total labile NeuNAc. In (a) G GNT 1 is represented by ( $\square$ ) and G Lac 1 by $(\boldsymbol{\Delta})$.

Table 1. Comparison of specific radioactivities of neuraminidase-resistant and -labile sialyl groups of brain gangliosides after injection of $\left[\mathrm{U} \cdot{ }^{14} \mathrm{C}\right]$ glucose into 8-day-old rats

Each animal received an intraperitoneal injection of $16 \mu \mathrm{Ci}$ of $\left[\mathrm{U}-{ }^{14} \mathrm{C}\right] \mathrm{glucose}$. The gangliosides and their corresponding sialyl groups were isolated and purified as described in the Experimental section. Twelve rats were used for each determination.

\begin{tabular}{|c|c|c|c|c|c|c|c|}
\hline \multirow{3}{*}{$\begin{array}{c}\text { Time } \\
\text { after } \\
\text { injection } \\
\text { (h) }\end{array}$} & \multicolumn{7}{|c|}{ Specific radioactivity (c.p.m. $/ \mu \mathrm{mol}$ of NeuNAc) } \\
\hline & \multirow{2}{*}{$\begin{array}{l}\text { G GNT } 1 \\
\text { Resistant }\end{array}$} & \multicolumn{2}{|c|}{ G GNT 2a } & \multicolumn{2}{|c|}{ G GNT 2b } & \multicolumn{2}{|c|}{ G GNT 3} \\
\hline & & Resist & Labile & Resist & Labile & Resist & Labile* \\
\hline 2 & 2580 & 2579 & 2410 & 2379 & 2451 & - & 1919 \\
\hline 5 & 3564 & 3235 & 3300 & 3310 & 3981 & 2512 & 2472 \\
\hline 24 & 5110 & 5177 & 5086 & 4924 & 5406 & 4813 & 4815 \\
\hline
\end{tabular}

* For G GNT 3 the values for the labile fraction represent the total labile NeuNAc.

the galactosyl groups proximal and distal to the ceramide moiety from a mixture of the major gangliosides were determined in 8-and 18-day-old rats. Results showed (Table 2) that, similarly to what was observed for the neuraminidase-resistant and -labile NeuNAc groups, the specific radioactivities of the two galactose units were essentially the same at any time after injection.

\section{DISCUSSION}

Although in experiments in vitro complex gangliosides were synthesized by stepwise addition of glycosidic groups to simpler gangliosides, the results of experiments in vivo by Suzuki \& Korey (1964), Arce et al. (1970) and those reported in the present work failed to show precursor-product 


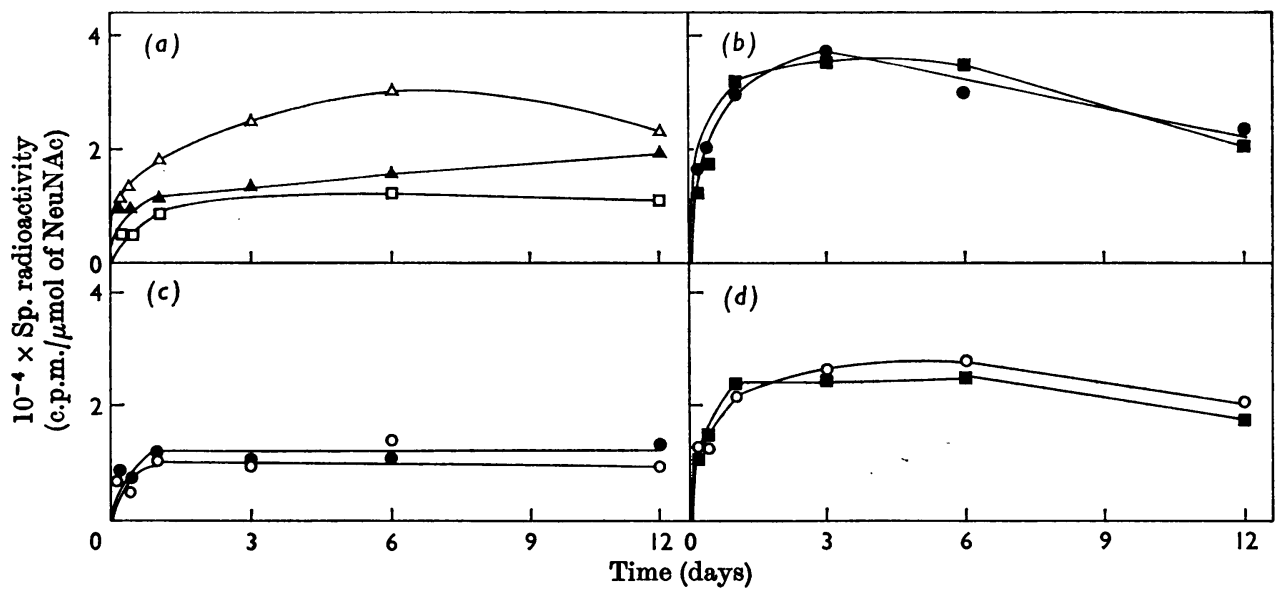

Fig. 3. Labelling of NeuNAc groups from different brain gangliosides as a function of time after intracisternal injection of $5 \mu \mathrm{l}$ of saline containing $50 \mu \mathrm{Ci}$ of $\left[6^{-3} \mathrm{H}\right]$ glucosamine into 18-day-old rats. The following symbols are used in the cases of G GNT $2 a(b)$, G GNT $2 b(c)$ and G GNT $3(d): \bullet$, neuraminidase-resistant NeuNAc; $\mathrm{O}$, neura minidase-labile NeuNAc, $(2 \rightarrow 3)$-linkage; $\square$, neuraminidase-labile NeuNAc, $(2 \rightarrow 8)$-linkage. In $(a)$ : $\square$, G GNT1; $\triangle$, G GNTr 1; $\triangle$, G Lac 1 .

Table 2. Labelling of the neutral hexoses of brain gangliosides isolated from rats after injection of $\left[\mathrm{U}_{-}{ }^{14} \mathrm{C}\right]-$ glucose

Twelve rats (8 days old) or eight rats (18 days old) were used for each determination. They received, respectively, 16 and $20 \mu \mathrm{Ci}$ of [U-14 $\mathrm{C}$ ]glucose by the intraperitoneal route. The hexoses were determined as described in the Experimental section.

\begin{tabular}{|c|c|c|c|c|c|c|}
\hline \multirow{3}{*}{$\begin{array}{c}\text { Time } \\
\text { after } \\
\text { injection } \\
\text { (h) }\end{array}$} & \multicolumn{6}{|c|}{ Specific radioactivity (c.p.m./ $\mu \mathrm{mol}$ of hexose) } \\
\hline & \multicolumn{3}{|c|}{ 8-day-old rats } & \multicolumn{3}{|c|}{ 18-day-old rats } \\
\hline & Glucose & $\begin{array}{c}\text { Proximal* } \\
\text { galactose }\end{array}$ & $\begin{array}{c}\text { Distal* } \\
\text { galactose }\end{array}$ & Glucose & $\begin{array}{c}\text { Proximal* } \\
\text { galactos } \theta\end{array}$ & $\begin{array}{c}\text { Distal* } \\
\text { galactose }\end{array}$ \\
\hline 2 & 5092 & 5260 & 6540 & - & - & - \\
\hline $\mathbf{5}$ & 6270 & 6875 & - & 3900 & $\mathbf{3 3 0 0}$ & 一 \\
\hline 10 & 一 & - & - & 3093 & 3400 & 3119 \\
\hline 24 & 5303 & 5988 & 6384 & 3000 & 3497 & 2981 \\
\hline
\end{tabular}

relationships between simple and complex gangliosides. The situation appears similar to that of the synthesis of neuraminlactose. From enzyme experiments lactose was assumed to be the normal precursor of neuraminlactose (Jourdian, Carlson \& Roseman, 1963) but after labelled glucose was given to lactating rats the rates of labelling of lactose and neuraminlactose were practically identical (Carubelli, Taha, Trucco \& Caputto, 1964). An explanation for this apparent discrepancy was given by Barra, Cumar \& Caputto (1969), who in experiments in vitro showed that synthesis of neuramin from free lactose must be negligible compared with that occurring when the synthesis of lactose and the subsequent binding of the sialyl group is carried out by one and the same enzyme complex.

Assuming that the notion originating from experiments in vitro on the biosynthesis of gangliosides is correct, i.e. that the carbohydrate chain grows by stepwise addition of one glycosyl group at a time and at the non-reducing end of the chain, the representation of their synthesis given in Scheme 1 is consistent with the findings in vivo and in vitro. The gangliosides are pictured as continually bound to structural parts of the cell during their synthesis, forming a multienzyme-substrate complex. This complex was indicated by kinetic experiments with endogenous acceptors (Arce et al. 


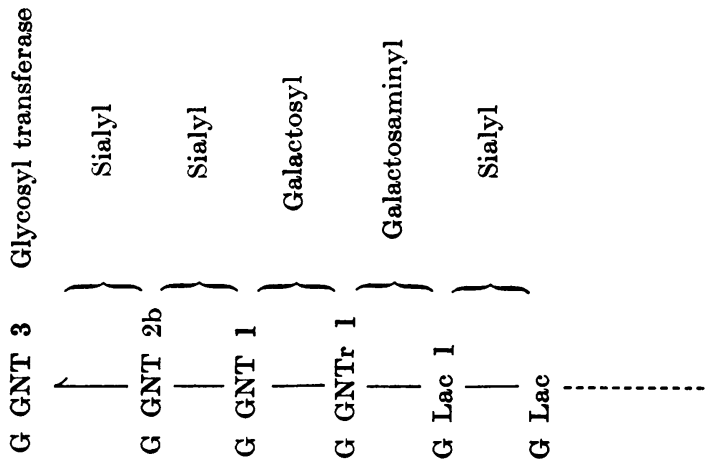

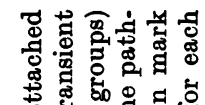

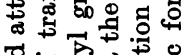

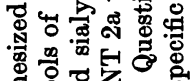

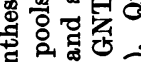

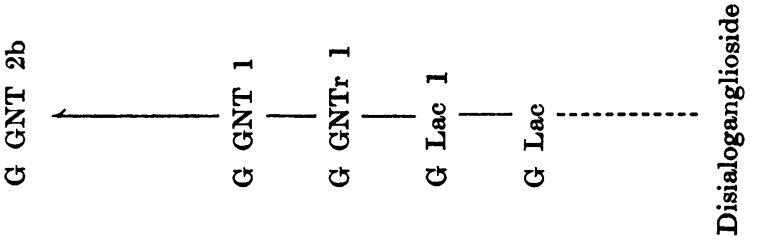

.

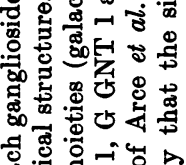
ङ.

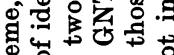

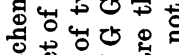

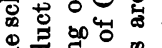
형 五

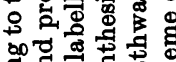

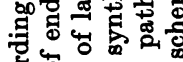

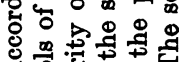

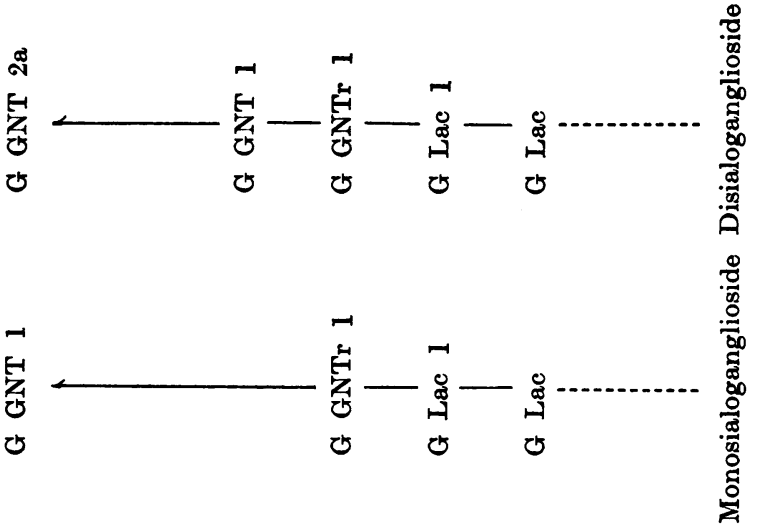

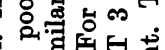

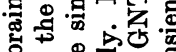

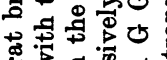

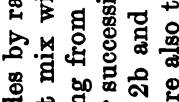
过

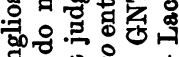
总要范すర

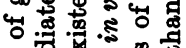
兽过思置

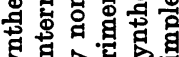

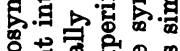

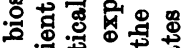
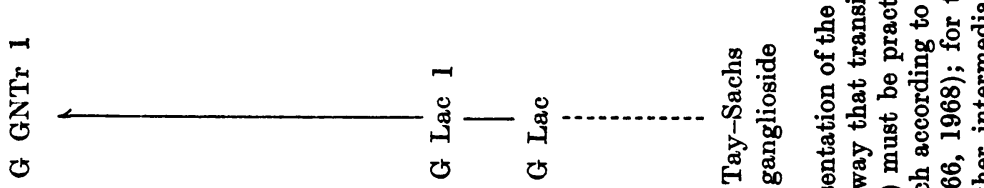

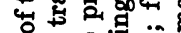
范罗究前焉

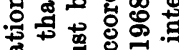

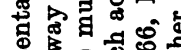

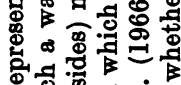

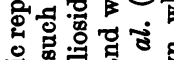

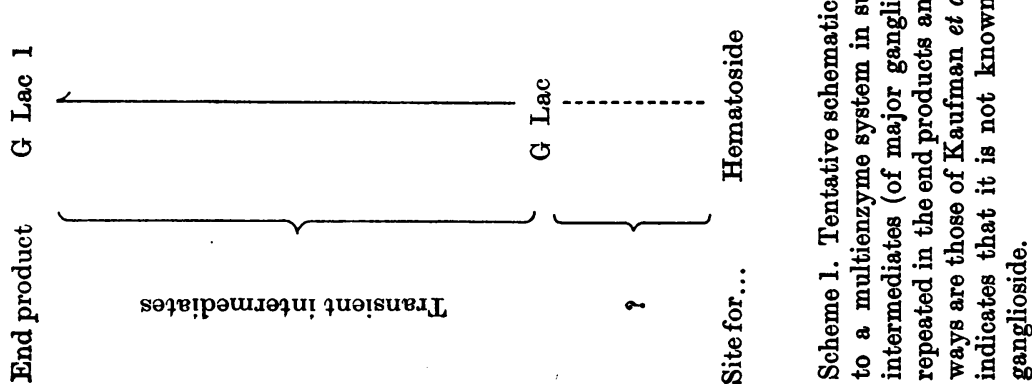


1971) and explains how any simple (or precursor) ganglioside may be transformed into a more complex one without undergoing dilution in passing through successive pools of intermediates, as should occur if those intermediates were free in solution. A lack of precursor-product relationship was also observed in experiments in vitro with endogenous acceptors. The representation in Scheme 1 is also consistent with the observation that some of the more complex gangliosides were labelled at faster rates than any particular simpler precursor. To be so, the pool of the compound that was an intermediate for the more complex ganglioside has to be independent of the pool of the identical compound that was synthesized as end product. The pool of end product must be large by comparison with that of intermediate compound(s) and formed at a slower rate than that of the more complex ganglioside. A factual example is provided by the labelling of hematoside : in all of the pathways so far proposed, the hematoside is a precursor of more complex gangliosides; however, the specific radioactivities of the neuraminidase-resistant NeuNAc moieties from G GNT 2b or G GNT 3 obtained in the experiments with labelling in vivo were higher than that of NeuNAc from hematoside at any time after $\left[6-{ }^{3} \mathrm{H}\right]$ glucosamine was given to rats. To make the pathways proposed compatible with these last observations, the pools of hematoside that are transient intermediates (Scheme 1) in the formation of G GNT 2b or G GNT 3 have to be independent and small in relation to the pool of end-product hematoside; this last mentioned pool should be formed or turned over at a slower rate than the pool of end-product G GNT $2 \mathrm{~b}$ or G GNT 3.

In relation to the sizes of the pools of transient intermediates, the following observations are pertinent: from the stages of glucosyl ceramide, at least, to that previous to the final products the pools of transient intermediates have to be relatively very small; so much so that they are almost nonexistent. This explains why, in rats that have received suitable labelled precursors, the specific radioactivities of the sialyl groups resistant and labile to the neuraminidase of each disialoganglioside were identical, and accounts for the same occurrence with the two labile NeuNAc groups from trisialoganglioside and for the galactosyl groups proximal and distal to the ceramide moiety. This could not occur if there was a significant amount of transient G Lac 1 or any more complex intermediates ready to be completed to either monoor multi-sialogangliosides. This also indicates that normally there is no independent turnover of components of the carbohydrate chain in vivo; once a ganglioside starts to be degraded it must go all the way, at least to lactosylceramide (as concluded from the labelling of sialyl groups) or glucosylceramide (as concluded from the labelling of galactosyl groups) before it can begin to be rebuilt. Whether glucosylceramide or even earlier intermediates are also transient is not known a present.

A noticeable difference between the 8- and 18day-old rats was that in the former no clear differences could be established between the major gangliosides whereas in the 18-day-old rats two groups could be distinguished: one group having the NeuNAc- $(2 \rightarrow 8)$-NeuNAc linkage (G GNT 2b and G GNT 3), which was labelled at a faster rate than the other group, consisting of G GNT 1, G GNT $2 a$ and G GNTr 1.

This investigation was supported in part by a grant from the Consejo Nacional de Investigaciones Científicas y Técnicas, Argentine Republic, and by Grant NB 04781 from National Institutes of Health, U.S. Public Health Service. The helpful criticism by $\mathrm{Dr}$ H. S. Barra is acknowledged.

\section{REFERENCES}

Aminoff, D. (1961). Biochem. J. 81, 384.

Arce, A., Maccioni, H. J. \& Caputto, R. (1966). Archs Biochem. Biophys. 116, 152.

Arce, A., Maccioni, H. J. \& Caputto, R. (1970). Fedn Proc. Fedn Am. Socs exp. Biol. 29, 410.

Arce, A., Maccioni, H. J. \& Caputto, R. (1971). Biochem. $J .121,483$.

Barra, H. S., Cumar, F. A. \& Caputto, R. (1969). J. biol. Chem. 244, 6233.

Carubelli, R., Taha, B., Trucco, R. E. \& Caputto, R. (1964). Biochim. biophys. Acta, 83, 224.

Cumar, F. A., Barra, H. S., Maccioni, H. J. \& Caputto, R. (1968). J. biol. Chem. 243, 3807.

Cumar, F. A., Fishman, P. H. \& Brady, R. O. (1971). J. biol. Chem. (in the Press).

Folch, J., Lees, M. \& Sloane-Stanley, G. H. (1957). J. biol. Chem. 226, 497.

Gal, A. (1968). Analyt. Biochem. 24, 452.

Jourdian, G. W., Carlson, D. M. \& Roseman, S. (1963). Biochem. biophys. Res. Commun. 10, 352.

Kaufman, B., Basu, S. \& Roseman, S. (1966). Proc. $3 r d$ int. Symp. Cerebral Sphingolipidoses, p. 193. Ed. by Aronson, S. M. \& Volk, B. N. New York: Pergamon Press Inc.

Kaufman, B., Basu, S. \& Roseman, S. (1968). J. biol. Chem. 243, 5804.

Kuhn, R. \& Wiegandt, H. (1964). Z. Naturf. 196, 256.

Ledeen, R., Selsman, K. \& Cabrera, M. (1968). Biochemistry, Easton, 7, 2287.

Miettinen, T. \& Takki-Luukkainen, I. T. (1959). Acta chem. scand. 13, 856.

Suzuki, K. \& Korey, S. R. (1964). J. Neurochem. 11, 647.

Trevelyan, W. E. \& Harrison, J. S. (1952). Biochem.J. 50, 298.

Wells, M. A. \& Dittmer, J. C. (1963). Biochemistry, Easton, 2, 1259

Wiegandt, H. (1968). Angew. Chem. 80, 89. 